Mark A. Moline - Barbara B. Prézelin

\title{
High-resolution time-series data for 1991/1992 primary production and related parameters at a Palmer LTER coastal site: implications for modeling carbon fixation in the Southern Ocean
}

\begin{abstract}
Our goal was to provide a high-resolution temporal data base for modeling primary production in shelf waters adjacent to Palmer Station, Antarctica. Here, the resulting 1991/1992 data base is used to: (1) determine in situ productivity over a range of seasonal to subseasonal time scales; (2) identify time scales of significant variability in marine productivity during the peak growing season; (3) identify environmental, experimental and analytical factors that can significantly impact the accuracy of daily, weekly and seasonal productivity estimates; and (4) integrate our findings with previous studies of Antarctic coastal primary production. Data were gathered every $2-3$ days during a 3-month period in the austral spring/summer of 1991/1992. Photosynthesis-irradiance (P-I) relationships were determined throughout the euphotic zone and P-I parameters, combined with knowledge of the in-water light field, were used to derive instantaneous rates of in situ primary production. Additionally, weekly samples were collected from surface and chlorophyll a maxima for characterization of the patterns of diel periodicity in P-I parameters. Seven diel patterns were discerned over the season and used to time-correct instantaneous measurements and derive noontime, daily, monthly and seasonally integrated estimates of production. During the season, a large bloom was responsible for some of the highest daily productivity rates reported for the Southern Ocean $\left(0.8 \mathrm{~g} \mathrm{C} \mathrm{m}^{-3} \mathrm{~d}^{-1}, 6.3 \mathrm{~g} \mathrm{C} \mathrm{m}^{-2} \mathrm{~d}^{-1}\right)$. Significant variation in daily integrated rates occurred generally on time scales less than a week. Peak timing and magnitude of daytime periodicities in photosynthesis varied widely over the season, closely coupled to changes in phytoplankton community composition. Instantaneous measurements of primary production, if
\end{abstract}

uncorrected or improperly corrected for daytime periodicities in carbon fixation, were unreliable predictors of production on longer time scales even if the water column was sampled every few days. High frequency sampling and consideration of diel periodicity may be requirements when attempting to discern differences between short time-scale variability and longterm trends in Antarctic primary production.

\section{Introduction}

The Southern Ocean supports a rich biotic ecosystem, ultimately dependent on autotrophic production by phytoplankton. Many previous studies have documented large spatial variations in primary productivity (cf. Holm-Hansen et al. 1977; El-Sayed et al. 1983; Bodungen et al. 1986; Wilson et al. 1986; HolmHansen and Mitchell 1991; Helbling et al. 1995). Production associated with marginal ice zones (cf. Smith and Nelson 1985; Holm-Hansen and Mitchell 1991; Prézelin et al. 1994) and coastal shelf regions (cf. ElSayed and Weber 1982; Holm-Hansen and Mitchell 1991; Prézelin et al. 1992a) is generally higher than in offshore waters, which are characteristically oligotrophic (Smith and Sakshaug 1990; Sakshaug et al. 1991). Few studies, however, have examined the temporal variability in primary productivity in any of these regions: exceptions include Horne et al. (1969), who sampled coastal waters at South Orkney Island every 5-6 days over a period of 1 month; Whitaker (1982), who sampled the same sites as Horne et al. (1969) but with a sampling frequency of ca. 20 days over a 2-year period; Holm-Hansen and Mitchell (1991), who sampled four sites in coastal waters along the Palmer Peninsula at 20-day intervals for a 4-month period; and Rivkin (1991), who sampled McMurdo Sound every 5-6 days for a period of 5 months. Recent analyses of sampling frequency effects on error estimates of primary production (Taylor and Howes 1994) suggest, 
however, that the above sampling regimes may not be sufficient to resolve significant variations in local production that occur on shorter (less than 1 week) times scales. If true, unknown errors would be included in derived production estimates on longer time scales, with ramifications for ecosystem modeling and interpretation of seasonal dynamics in phytoplankton communities of the Southern Ocean.

The Palmer LTER is a multidisciplinary program established in 1990 (Ross and Quentin 1992). It seeks to understand and model predictive interactions between different marine trophic levels and the chemical/ optical/physical environment of coastal waters in the Southern Ocean. Work was defined in the context of common goals and philosophy of the U. S. LTER Network, which included requirements for the definition of patterns and control of primary production within the LTER study site along the Palmer Peninsula, as well as spatial and temporal distributions of populations representing different trophic structures. With relatively little background data, starting up a long-term research program required much attention to both field program design and intensive data collection in order to assure the ability to eventually distinguish between natural short-term variability and long-term trend due to natural cycles (i.e. ice coverage) or unnatural environmental perturbations brought on by global climate change (i.e. global warming, ozone diminution).

Sampling of time-series stations within $5 \mathrm{~km}$ of Palmer Station was particularly intense in the 1st year of the program (1991-1992), as phytoplankton dynamics were thought likely to change significantly over small time and space scales, with serious implications for interpretation of long-term data sets and sampling strategies. To this end, carbon fixation rates were determined on an average of every $2-3$ days to estimate instantaneous, daily and monthly simulated in situ rates of primary productivity for the 3 -month springsummer period. Uncertainty of the timing and magnitude of daily changes in production, known to introduce significant errors in estimates of in situ rates of primary production in both temperate (cf. Harding et al. 1982; Prézelin et al. 1987; Smith et al. 1987; Prézelin and Glover 1991) and polar latitudes (Rivkin 1987; Rivkin and Putt 1988), made it also necessary to measure and incorporate diel variation in the rate estimates for the season. The resulting high-resolution time-series data set, collected for a single LTER station, is employed here to: (1) determine simulated in situ productivity on time scales and for durations not previously reported for the Antarctic; (2) identify time scales of significant variability in productivity during the peak growing season in these largely uncharacterized locations, so that perhaps less resolved sampling strategies could be justified in following LTER field seasons; (3) determine and examine factors that may significantly affect daily, weekly and seasonal pro- ductivity estimates; and (4) integrate our results with previous studies of Antarctic coastal primary production. These findings would provide insights and advancements in primary production estimates useful to the planning of other multidisciplinary programs (i. e. GLOBEC and JGOFS), which share similar goals of ascertaining the differences between short-term variability and long-term trends in primary production in diverse regions of the Southern Ocean.

\section{Materials and methods}

\section{Sampling}

From 3 December 1991 until 27 February 1992, a total of 249 discrete water samples were collected at the LTER Station B (Sta. B; Fig. 1) for concurrent determinations of physical, optical, biological and chemical parameters related to phytoplankton ecosystem dynamics. Prior to collection, vertical profiles of photosynthetically available radiation $\left(400-700 \mathrm{~nm}, \mathrm{Q}_{\mathrm{par}}\right)$ and temperature were measured. In addition, in situ chlorophyll (Chl) fluorescence profiles were measured (Smith et al. 1992a). From the light and fluorescence profiles, subsurface sampling depths were preselected to include the surface, Chl $a$ maximum (Chl $a$ max), the $30 \%, 12 \%, 7 \%$ and $3 \%$ $\mathrm{Q}_{\text {par }}$ light levels and usually one sample near the bottom $(\sim 65 \mathrm{~m})$. Sampling was conducted from a Mark V Zodiac with an effort made to sample near solar noon. Whole-water samples were collected in cleaned 5-1 GoFlo bottles, transferred to acid-washed dark bottles and returned to Palmer Station within $30 \mathrm{~min}$, where samples remained in a cold room $\left(-2^{\circ} \mathrm{C}\right)$ until analyses were performed.

\section{HPLC pigment analysis}

Aliquots of all whole-water samples were analysed for the algal pigments using reverse-phase HPLC procedures described by Bidigare et al. (1989). One-liter samples were filtered on $0.4-\mu \mathrm{m}$ nylon $47-\mathrm{mm}$ Nuclepore filters and extracted in $3 \mathrm{ml} 90 \%$ acetone for $24 \mathrm{~h}$ in the dark at $-20^{\circ} \mathrm{C}$. Pigment separation was achieved with the aid of an Hitachi L-6200A liquid chromatograph equipped with a Waters Radial-PAK $C^{18}$ column $(8 \times 100 \mathrm{~mm}$ column; $5-\mu \mathrm{m}$ particles) and an Hitachi L-4250 UV/VIS Variable Wavelength Detector $(436 \mathrm{~nm})$. Peak identities of algal extracts were determined by comparing their retention times with pure pigment standards. For the purposes of the present study, temporal/spatial patterns are presented only for the chemotaxomic marker pigments $\mathrm{Chl} a$ (an indicator of total phytoplankton biomass), alloxanthin (a marker for cryptophytes), 19-hexanoyloxyfucoxanthin (an indicator of prymnesiophytes, and in Antarctica a particular marker for Phaeocystis spp.) (Bidigare et al. 1995), 19'-butanoyloxyfucoxanthin (indicator of chrysophytes), and fucoxanthin (a diatom marker in Antarctica where fucoxanthin is not abundant in the major prymnesiophyte, Phaeocystis spp.). For additional details on the seasonal dynamics of algal pigmentation at Sta. B, as well as surrounding LTER nearshore transect stations, see Prézelin et al. (1992b) and Moline et al. (1996).

$\mathrm{Q}_{\mathrm{par}}$ measurements

Surface and in-water fluxes of $\mathrm{Q}_{\mathrm{par}}(400-700 \mathrm{~nm})$ were measured, respectively, with a Biospherical scalar irradiance meter (QSR170DT) equipped with a QSR-240 reference sensor and a QSP100DT underwater sensor. A second QSR-240 sensor was 
positioned next to outdoor incubators at Palmer Station where diel patterns of simulated in situ primary production were determined (see below). Incident $Q_{\text {par }}$ was recorded continuously every 5 min over the 3-month period. A comparison between the two QSR-240 sensors showed that $Q_{\text {par }}$ readings differed by $<5 \%$. Theoretical clear-sky maxima of daily integrated $Q_{\text {par }}\left(\mathrm{E} \mathrm{m}^{-2}\right)$ over the season were calculated from Morel (1991) and D. Antoine (personal communication) using an atmospheric correction (350 DU for ozone content and $2 \mathrm{~cm}$ precipitable water content). Bio-optical nomenclature used throughout this study is from Prezelin et al. (1993b).

Photosynthesis-irradiance relationships

On 39 days over the course of the sampling season, a total of 397 photosynthesis-irradiance (P-I) curves were determined for watercolumn samples collected from Sta. B. Of these, 181 P-I relationships were measured immediately after field collection for determinations of "instantaneous" rates of primary production. The remaining 216 P-I curves represent the 12 weekly analyses of diel variations in P-I parameters in both surface and Chl a max samples (see below).

All P-I measurements were made in blue-green light $\left(\mathrm{CuSO}_{4}\right.$ filters) $Q_{\text {par }}$ photosynthetrons, using established radiolabelled $\mathrm{H}^{14} \mathrm{CO}_{3}$ uptake procedures (Prézelin et al. 1989; Prézelin and Glover 1991). Blue-green light fields more closely mimic in-water spectral conditions in clear ocean waters and tend to release cells from artificial white light (or far-red) effects, which can reduce carbon uptake rates and photosynthetic quantum efficiencies (Prézelin et al. 1989; Schofield et al, 1991). Incubation times were kept to $90 \mathrm{~min}$ and incubation temperatures were controlled to within $0.2 \mathrm{C}$ of in situ temperatures. After incubation, samples were fixed with $20 \mu \mathrm{l}$ formalin solution, acidified with glacial acetic acidmethanol (1:30), and heat dried (Prézelin and Glover 1991). Dried samples were resuspended in $1 \mathrm{ml}$ of deionized water before National Diagnostics Liquiscint scintillation fluor was added. Quench-corrected disintegrations per min were determined on an LKB 1217 liquid scintillation counter.

Non-linear curve fits for P-I data were calculated using the Simplex method of Caceci and Cacheris (1984). Curve fitting provided the photosynthetic parameters $\mathrm{P}_{\max }$ (the light-saturated photosynthetic potential), $z$ (the light-limited photosynthetic efficiency), $\mathrm{I}_{\mathrm{k}}\left(=\mathrm{P}_{\max } / \alpha\right.$; an estimate of the minimum irradiance required for the onset of light-saturated photosynthesis), $\beta$ (the efficiency of photoinhibition) and $I_{t}$ (the irradiance threshold for the onset of photoinhibition). Estimates of the standard deviations for the P-I parameters were calculated using the procedures described by Zimmerman et al. (1987).

The derived P-I parameters from the nearly 400 P-I curves formed the data base for bio-optical modeling of in situ primary production in the present time series. To increase the accuracy of our estimates for primary production on different time scales, we eliminated from the data base any $\mathrm{P}_{\max }$ values with standard deviation estimates $>25 \%$ of the parameter value and any $\alpha$ value with a standard deviation $>30 \%$. This reduced the size of the productivity data base by less than $10 \%$. When $Q_{\text {par }}$-photoinhibition was evident, standard deviations for $\beta$ and $I_{1}$ were often large as a result of a limited number of high irradiance data points. However, given that $Q_{\text {par }}$-photoinhibition was rarely predicted at in situ irradiances (data not shown), uncertainty in $\beta$ values would have had little impact on the accuracy of simulated in situ productivity estimates in the present study on time scales longer than 1 day.

\section{Diel measurements}

On 12 occasions over the 3 -month time period. 10 liter samples were collected from both the surface and the $\mathrm{Chl} a$ max to determine the

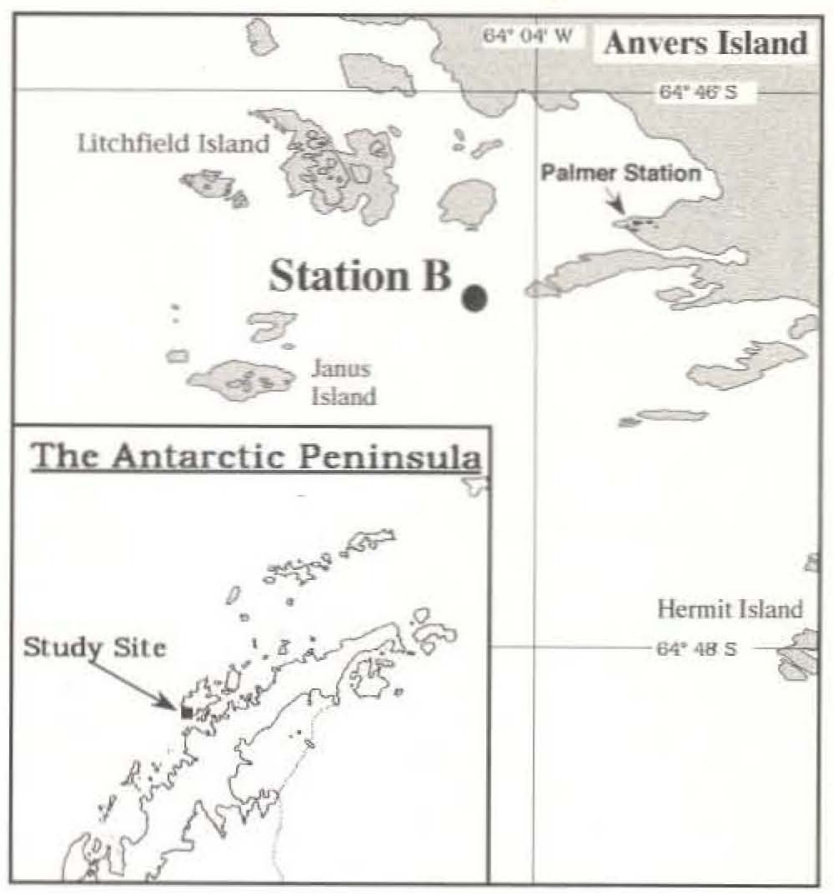

Fig. 1 Location of LTER sampling station B $\left(64^{\circ} 46.45^{\prime} \mathrm{S}, 64\right.$ 03.27 W) with respect to Palmer Station and (inset) the Antarctic Peninsula

diel variation in the P-I parameters. Samples were placed in large Pyrex carboys, screened with neutral density screening to the in situ $\mathrm{Q}_{\text {par }}$ light level at the depth of collection (surface was screened to $50 \%$ transmission), and incubated outdoors in a seawater tank at ambient temperatures for $24-30 \mathrm{~h}$. Subsamples were retrieved from the carboy at 3 -h intervals for determination of pigmentation and P-I relationships, using the procedures outlined above. The day:night variations in P-I parameters were plotted in order to resolve the time of day when the parameter reached its maximum value (i. e. $\max P_{\max }$ ) and to quantify the magnitude (i. e. maximum:minimum ratio) of the daytime variation in each P-I parameter. If diel patterns for the absolute variations in a P-I parameter (i. e. $P_{\max }$ ) were overlaid for different days that were deemed comparable (see below), a similar pattern was found but with different absolute. To compare the timing and magnitude of diel variations on different days, each diel pattern was normalized to its maximum value for that day (i. e. $P_{\max }: \max _{\max }$ ) (Fig. 2).

It should be noted that since $1 / 4$-inch Pyrex does not transmit solar ultraviolet radiation reaching the earth surface (ca. $295-400 \mathrm{~nm}$ ) at wavelengths less than ca. $324 \mathrm{~nm}$. incubated samples may have been released or were possibly recovering from UVB $(295-320 \mathrm{~nm})$ inhibition during the diel studies. A previous study of natural communities of Phaeocystis spp. under the influence of the 1990 ozone "hole" indicated that these phytoplankters were immediately released from all UVB inhibition when placed in $Q$. only incubators (Prézelin et al. 1994). With respect to UVA radiation $(320-400 \mathrm{~nm})$, our studies of Antarctic phytoplankton show it to be generally photoinhibitory and sometimes photosynthetically useful depending upon circumstances (Prézelin et al. 1994). The incorporation of UV inhibition, with consideration of the mixing regimes and in situ light histories, cannot yet be adequately addressed in this portion of the LTER field program. We, therefore, take a conservative approach to estimating simulated in situ rates of primary production and assume the diel patterns determined in the outdoor incubators are for $Q_{\text {par }}$-rates of photosynthesis only. 


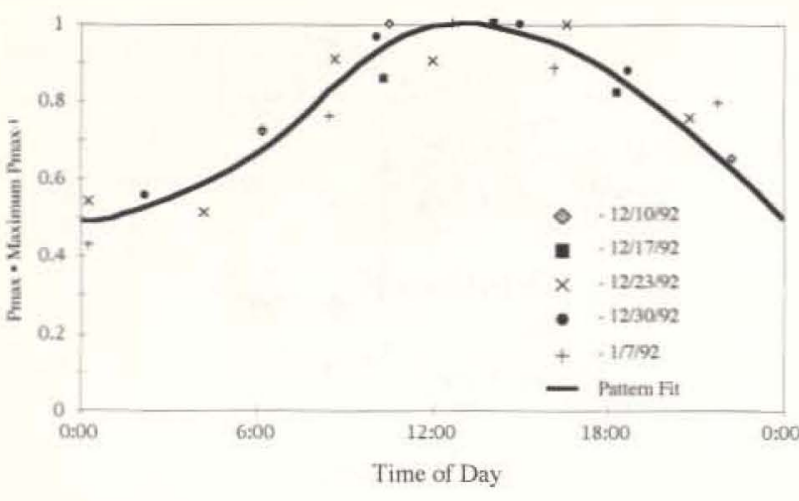

Fig. 2 Comparison of the normalized patterns for diel measurements of volumetric $\mathrm{P}_{\max }$ for five dates between 12 December 1991 and 7 January 1992, when a diatom bloom dominated the phytoplankton assemblage at LTER Sta. B. Each diel pattern is normalized to the peak value for $\mathrm{P}_{\max }$ measured on that day, i. e. the daytime variation in the ratio $\mathrm{P}_{\max }$ : $\max \mathrm{P}_{\max }$ is plotted and compared for each diel sampling date. The solid line indicates a manual fit for the diel measurements and is used to time-correct instantaneous measurements in order to calculate integrated daily rates of primary production (see text for details)

\section{Calculation of simulated in situ primary productivity}

Before the simulated in situ estimates of primary production could be calculated, it was necessary to first evaluate the different diel periodicity patterns of $\mathrm{P}-\mathrm{I}$ parameters and then to determine which patterns to assign to different instantaneous samples in order to generate time-dependent rates of primary production. The approach was very similar to that developed for time-correcting photosynthetic data to get a near synoptic view of in situ productivity off coastal California (Prézelin et al. 1987; Smith et al. 1987; Smith et al. 1989) and in the Sargasso Sea (Prézelin and Glover 1991). Diel patterns for each $\mathrm{Chl} a$-specific P-I parameter were sorted based upon shared biological and physical characteristics (i.e. water-mass type, pigment composition, location in water column and temporal occurrence over the season). As a result of these analyses, seven distinct sets of diel patterns of variations in $\mathrm{P}_{\max }$ and $\alpha$ were revealed over the season. Each normalized diel pattern for a P-I parameter (i. c. Fig. 2 for pattern I) was manually fit and then interpolated at 2-h intervals over the day, thereby allowing any instantaneous determination of any in situ P-I parameter to be extrapolated to an absolute diel pattern with the same $2 \mathrm{~h}$ resolution. $\mathrm{I}_{\mathrm{k}}$ was relatively constant for any individual diel measurements over the season, with $\alpha$ patterns always significantly correlated with $\mathrm{P}_{\operatorname{mix}}$ patterns $(P<0.0001)$. Daily $I_{k}$ patterns were therefore considered constant for calculations of simulated in situ productivity. Patterns for $\beta$ and $I_{4}$ were also determined for each diel measurement and incorporated in the calculations using the same criteria as for $\mathrm{P}_{\max }$ and $\alpha$.

Simulated in situ photosynthetic rates for a given depth and time $[\mathrm{P}(\mathrm{z}, \mathrm{t})]$ were calculated as a hyperbolic tangent (Neale and Richerson 1987),

$P(z, t)=P_{\max }(z, t) \cdot \tanh \left(\frac{Q_{\text {pat }}(z, t)}{I_{\mathrm{k}}(z, t)}\right)$

when $Q_{\text {par }}(\mathrm{z}, \mathrm{t})$, the in situ irradiance, was less than $I_{t}(\mathrm{z}, \mathrm{t})$ and

$$
\begin{aligned}
P(z, t)= & P_{\max }(z, t) \cdot \tanh \left(\frac{Q_{\mathrm{par}}(z, t)}{I_{\mathrm{k}}(z, t)}\right) \\
& \cdot \exp \left[-\beta\left(Q_{\text {par }}(z, t)-I_{t}(z, t)\right)\right]
\end{aligned}
$$

when $Q_{\text {par }}(z, t)$ was greater than $I_{4}(z, t)$. Resulting estimates of hourly in situ primary production, at 2-h intervals over the day, were then used to determine daily rates by trapezoidal integration at each discrete sampling depth. Trapezoidal integration was also used for calculating depth integrated rates, which were then integrated to estimate weekly, monthly and seasonal rates of primary production. Contour plots in this study were generated using the Delaunay triangulation method (DeltaGraph Pro3, DeltaPoint, Monterey, Calif., USA).

\section{Results}

\section{Seasonal light field variation}

Under clear sky conditions, it is the progressive changes in daylength and solar zenith angle (Fig. 3A) that determine seasonal changes in daily integrated irradiance (Fig. 3B) reaching any given location on earth. However, at LTER Sta. B from late spring through the summer of $1991 / 1992$, incident $Q_{\text {par }}$ was routinely less than the theoretical limit (Fig. 3B). On average, only $73 \pm 29 \%$ of daily $Q_{\text {par }}$ reached the study site over the course of the monitoring program (Fig. 3C). Fluctuations in daily integrated $\mathrm{Q}_{\text {par }}$ could vary two-to three-fold within a day or within two days of each other. On the time scales of a few weeks, daily

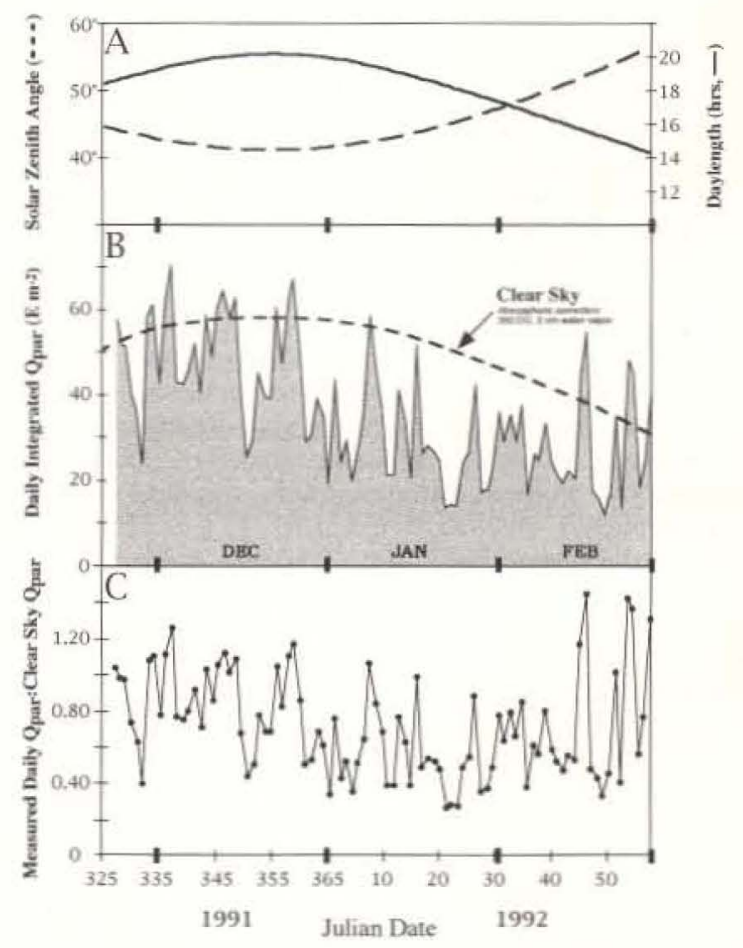

Fig. 3 A Seasonal changes in midday solar zenith angle (dashed line) and daylength (solid line) at the latitude (64. S) for Palmer LTER Sta. B sampled between 21 November 1991 (JD 325) and 27 February 1992 (JD 058). B Comparison of the seasonal changes in the measured (shaded area) and theoretical maximum (clear sky, dashed line) daily integrated $\mathrm{Q}_{\mathrm{par}}\left(\mathrm{E} \mathrm{m}^{-2} \mathrm{~d}^{-1}\right)$ for Palmer Station during the late austral spring and summer of 1991/1992. C Seasonal changes in the above-water ratio of measured:clear-sky flux of daily integrated $\mathrm{Q}_{\mathrm{par}}$ Palmer LTER Sta. B 
integrated $Q_{\text {par }}$ appeared to reflect the somewhat periodic nature of Antarctic storms and their associated increased cloud cover (Fig. 3B). Clearer sky conditions were more prevalent in early summer when the diatom bloom occurred and at the end of the field season in late February, 1992. During a storm event in the last week in January, only ca. $28 \%$ of daily $\mathrm{Q}_{\mathrm{par}}$ reached the study site. As in other studies (Holm-Hansen and Mitchell 1991), incident $Q_{\text {par }}$ was occasionally higher than the calculated maximum for clear skies and is thought to result from reflection by snow/ice cover.

Attenuation of surface $Q_{\text {par }}$ in the water column at LTER Sta. B varied greatly over the season, due to the 100 -fold variation in phytoplankton biomass (Fig. 4). $\mathrm{Chl} a$ concentrations ranged from 0.3 to $\mathrm{ca} .30 \mathrm{mg} \mathrm{Chl}$ $a \mathrm{~m}^{-3}$ over the late spring/summer season with the $1 \%$ surface $Q_{\text {par }}$ light level correspondingly varying between 60 and $10 \mathrm{~m}$. Two to 10 -fold fluctuations in phytoplankton standing stock and light attenuation were evident within any given week of sampling (Fig. 4). The rapid short-term fluctuations in daily integrated surface irradiance (Fig. 3B), phytoplankton biomass (Fig. 4A) and its effect on in situ attenuation coefficients for $\mathrm{Q}_{\text {par }}$ (illustrated by changing percent light depths in Fig. 4B) combined to determine the seasonal pattern of daily integrated in-water $Q_{\text {par }}$ at LTER Sta. B (Fig. 5A).

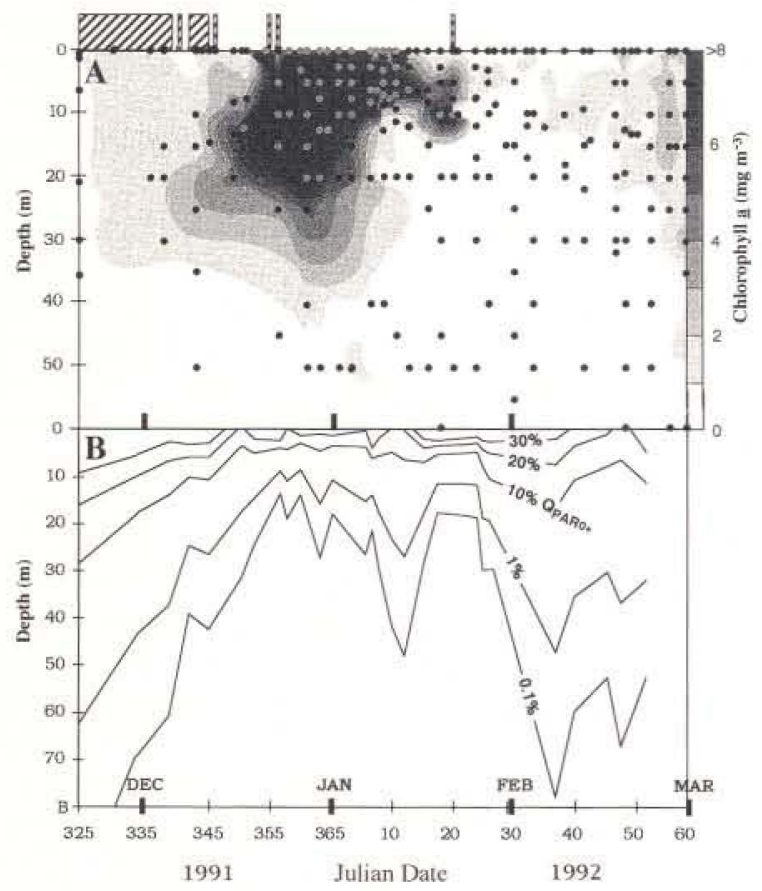

Fig. 4A-B Seasonal change in the depth distribution of A chlorophyll $a\left(\mathrm{mg} \mathrm{Chl} a \mathrm{~m}^{-3}\right)$ and B percent $\mathrm{Q}_{\text {par }}\left(0^{+}\right)$at LTER Sta. B from 21 November 1991 to 27 February 1992. The distribution of discrete samples collected for $\mathrm{Chl} a$ determinations is shown by filled circles. The presence of significant pack ice (i. e. $>50 \%$ coverage) is indicated by hatch bars. Note that contours of $\mathrm{Chl} a$ values in excess of $8 \mathrm{mg} \mathrm{m}^{-3}$ are not shown and that concentrations within the phytoplankton bloom were generally in excess of $20 \mathrm{mg} \mathrm{m}^{-3}$ (see text)
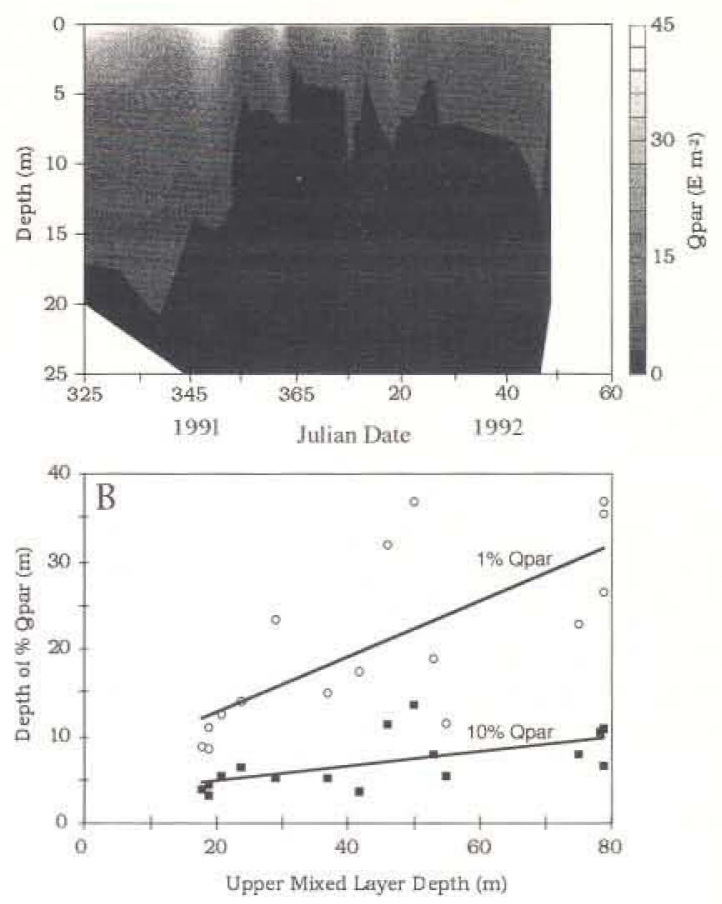

Fig. 5A Seasonal variation in the in-water daily integrated $Q_{\text {par }}$ at Palmer LTER Sta. B from 21 November 1991 to 21 February 1992. B Relationships between the $10 \%$ surface $Q_{\text {pur }}$ (solid squares) and $1 \%$ surface $Q_{\text {par }}$ (unfilled circles) light depths and the depth of the upper mixed layer (UML) at Palmer LTER Sta B. The $U M L$ was calculated using methods described in Mitchell and Holm-Hansen (1991). The presence of significant pack ice (i. e. $>50 \%$ coverage) is indicated by hatch bars

Water-column stability, as measured by the depth of the upper mixed layer [UML; Mitchell and HolmHansen (1991)], was found to be a major driving force for the accumulation of biomass in the water column at Sta. B through the first LTER season (Moline et al. 1996). Further evidence for this conclusion is the significant relationships between changes in the percent light depths and the depth of the UML (Fig. 5B). As phytoplankton biomass increased in response to the shallowing UML depth on time scales of 2 days, there was a corresponding decrease in the depth of the euphotic zone. Data regarding the photoadaptive responses and optimization of light utilization efficiency for photosynthesis during this period are discussed elsewhere (Schofield et al. 1994, Claustre et al. 1996).

Seasonal variations in phytoplankton community composition and diel patterns of photosynthesis

\section{Late spring and the initiation of a diatom bloom} with a midday peak in productivity

In late November 1991, the water column at Sta. B was ice-covered (Fig. 4) and the spring phytoplankton community was dominated by a mixed assemblage of diatoms (as indicated by the presence of fucoxanthin), 
prymnesiophytes $\left(19^{\prime}\right.$-hexanoyloxyfucoxanthin; in the Antarctic primarily Phaeocystis spp.) and chrysophytes (19'-butanoyloxyfucoxanthin) (Fig. 6). There were also indications of chlorophytes $(\mathrm{Chl} b)$ throughout the region (Prézelin et al. 1992b). The combination of relatively clear skies, low solar zenith angles, increasing daylength (Fig. 3) and low phytoplankton biomass (0.83 $\mathrm{mg} \mathrm{Chl} a \mathrm{~m}^{-3}$; Fig. 4) all contributed to the observation that the absolute solar insolation in the water column, even under surface ice, was at or near the highest values measured during the 1991/1992 spring/summer seasons (Fig. 5A). These bright light environments were confined to a fresher meltwater lens (FML) about $5 \mathrm{~m}$ deep with relatively low values of daily integrated $\mathrm{Q}_{\text {par }}$ in the well-mixed water below the FML (Fig. 7). Phytoplankton community composition of these two mixing regimes was not significantly different (Fig. 6), suggesting that the pycnocline separating the FML from the UML in the late spring might have

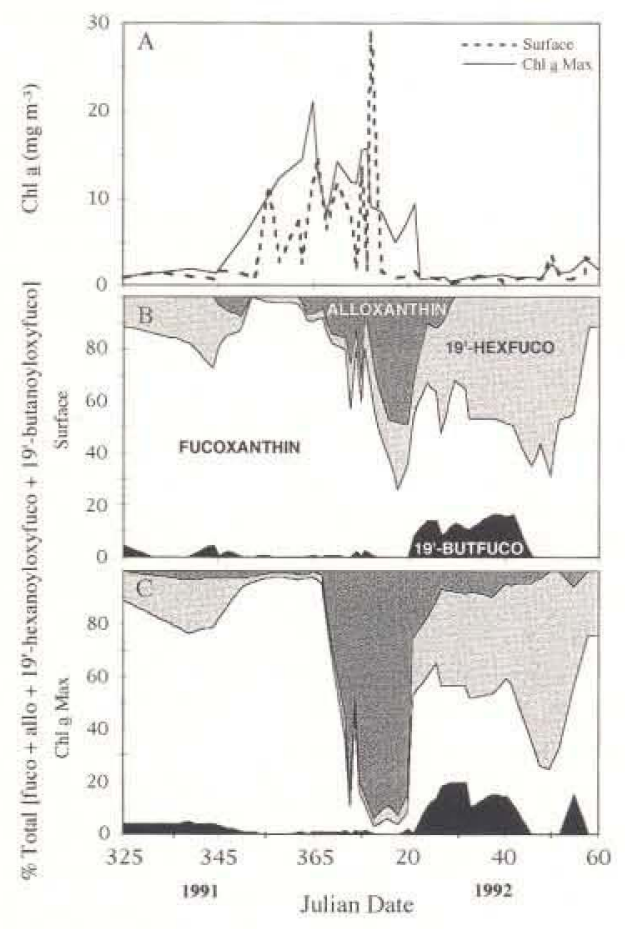

Fig. 6A-C Seasonal change in dominant phytoplankton groups in surface and $\mathrm{Chl}$ a max communities at Palmer LTER Sta. B from 21 November 1991 to 27 February 1992. A Comparison of the fluctuations in surface and $\mathrm{Chl} a$ max phytoplankton biomass. B Shifts in dominant phytoplankton groups in surface waters at LTER Sta. B, as indicated by changing percent contribution of each of four chemotaxonomic marker carotenoids to the sum total of the four pigments. C Same as B but for seasonal change in phytoplankton community composition within the $\mathrm{Chl} a$ max. Marker pigments include fucoxanthin for diatoms, alloxanthin for cryptophytes, $19^{\prime}$-hexanoyloxyfucoxanthin for prymnesiophytes, and 19'-butanoyloxyfucoxanthin for chrysophytes. Note that while surface samples were always collected within $0.5 \mathrm{~m}$ of the surface, the $\mathrm{Chl}$ a max sampling depths varied between 5 and $20 \mathrm{~m}$ over the season (Fig. 7)

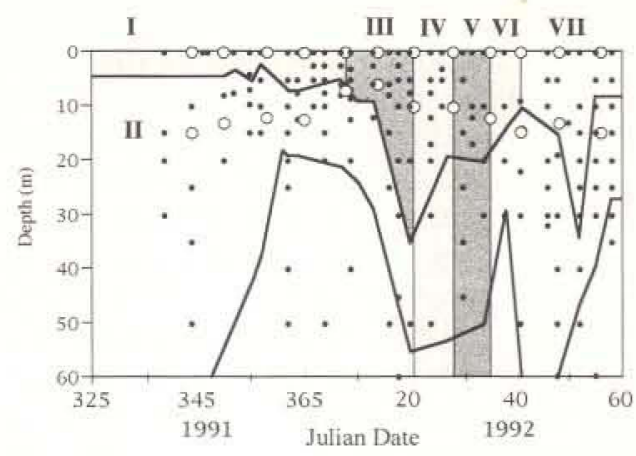

Fig. 7 Depth distribution of samples (all circles) collected for P-I curve determinations and calculations of simulated in situ productivity from 5 December 1991 to 27 February 1992. Large unfilled circles represent the times and depths of sample collection from surface waters and the Chl $a$ maxima for simulated in situ determinations of diel variations in P-I parameters. Overlaid are the calculated depths of the upper mixed layer (lower solid line) and fresher meltwater lens (upper solid line) (from Moline et al. 1996). Each shaded area indicates a composite of samples where a single diel pattern of variation in P-I parameters was applied to timecorrect instantaneous measurements to estimate daily integrated rates of primary production. Seven $(I-V I I)$ distinct patterns for diel variations in P-I parameters were resolved over the season (Figs. 8, 9) and are shown here to illustrate which patterns were applied to which discrete samples

been weak, i. e. setting up and breaking down on short time scales. Our observations of deep mixing below the FML in late November are consistent with measurements of high concentrations of inorganic nutrients throughout the water column, i. e. $\mathrm{NO}_{3}$ in excess of $30 \mu \mathrm{M}, \mathrm{Si}(\mathrm{OH})_{4}$ in excess of $40 \mu \mathrm{M}$, and $\mathrm{PO}_{4}^{3-}$ greater than $1 \mu \mathrm{M}$ (Moline and Prézelin 1994, Moline et al. 1996).

The local fast/pack ice broke up and was blown out of the area in early December 1991 (ca. JD 347) (Fig. 4A). There was a significant increase in the daily integrated in-water $Q_{\text {par }}$ (Fig. 4A), even though skies were exceedingly cloudy (Fig. 3B). As incident solar radiation increased during the last 2 weeks of December (Fig. 3B), the water temperature within the FML increased $2^{\circ} \mathrm{C}$, from $-1.3^{\circ} \mathrm{C}$ to $+1.3^{\circ} \mathrm{C}$. Decreased wind forcing during this period (Moline et al. 1996) shallowed the UML to within $20 \mathrm{~m}$ of the surface (Fig. 7). Concentrations of pigment biomarkers for prymnesiophytes and chrysophytes decreased throughout the water column while diatom pigmentation increased several fold (Prézelin et al. 1992b; Moline et al. 1996). A near unialgal bloom of Coscinodiscus spp., as confirmed by microscopic examination, persisted for 4 weeks in late spring/early summer (JD 340-JD 007) and came to account for more than $95 \%$ of the carotenoid pigmentation in both the surface and $\mathrm{Chl} a$ max at Sta. B (Fig. 6).

Chl $a$ concentrations during the Coscinodiscus spp. bloom were routinely between 15 and $25 \mathrm{mg} \mathrm{Chl}$ $a \mathrm{~m}^{-3}$ (Fig. 6A). At its peak on the last day of 1991, integrated water column $\mathrm{Chl}$ a biomass reached $612 \mathrm{mg} \mathrm{Chl} a \mathrm{~m}^{-2}$ (Moline et al. 1996). The rate of 
increase in Chl $a$ biomass over the lifetime of the bloom (i. e. from 0.3 to $30 \mathrm{mg} \mathrm{Chl} a \mathrm{~m}^{-3}$ ) was greater than that attributable solely to concentrating phytoplankton to a shallower UML. Preliminary estimates suggest Coscinodiscus spp. communities were doubling in biomass about once every 4 days. The impact of increased pigmentation on water clarity was evident during the bloom, with the $1 \% \mathrm{Q}_{\text {par }}$ level reduced to within $10 \mathrm{~m}$ of the surface and the $0.1 \% \mathrm{Q}_{\text {par }}$ level at $15 \mathrm{~m}$ (Fig. 4B).

It is not surprising that the development of a large diatom bloom also had a major impact on macronutrient distribution within the region (Prézelin et al. 1992b; Moline and Prézelin 1994; Moline et al. 1996). In brief, there was a highly significant linear relationship between $\mathrm{PO}_{4}^{3-}$ and $\mathrm{NO}_{3}$ before and after the diatom bloom, identical to that defined for much of the Southern Ocean (Kamykowski and Zentara 1989). However, the development and maintenance of this diatom bloom radically altered this linear chemical relationship, which previously had been suggested to be a diagnostic characteristic of the plant/nutrient interactions for Antarctic waters (Kamykowski and Zentara 1989). During the bloom, $\mathrm{PO}_{4}^{3-}$ and $\mathrm{NO}_{3}$ levels were depleted to below detection levels and $\mathrm{Si}(\mathrm{OH})_{4}$ levels were significantly reduced. $\mathrm{NO}_{3}: \mathrm{PO}_{4}^{3-}$ ratios tripled and $\mathrm{PO}_{4}^{3-}$ limitation of diatom growth was indicated by the later stages of the bloom in the 1st week of January 1992. When $\mathrm{PO}_{4}^{3-}$ and $\mathrm{NO}_{3}$ levels dropped below detection levels in surface waters, rates of diatom biomass increases slowed (Fig. 6A) and there was a small but detectable increase in Phaeocystis spp. concentrations (19'-hexanoyloxyfucoxanthin biomarker) in the low nutrient FML between JD 355, and JD 365 (Fig. 6B).

Primary production measurements at LTER Sta. B began on JD 339 (Fig. 7), just prior to the onset of the diatom bloom, and were made about every 3 days. Determinations of the diel periodicities in P-I parameters for bloom populations were measured once a week for surface and Chl $a$ max samples. The normalized diel patterns for daytime variations in $P_{\max }$ were very similar for each of the five weekly samples collected during the diatom bloom (Fig. 2). The single representative pattern, resolved from the pooled $\mathrm{P}_{\max }$ data for surface diatom communities (pattern I, Figs. 2,8), was characterized by an approximate two-fold change in $\mathrm{P}_{\max }$ over a 20 -h photoperiod with the peak timing of $P_{\max }$ (i. e. $\max P_{\max }$ ) occurring about an hour before solar noon (Fig. 7). $\mathrm{I}_{\mathrm{k}}$ values changed little over each day $\left(101 \pm 13 \mu \mathrm{E} \mathrm{m} \mathrm{m}^{-2} \mathrm{~s}^{-1}, n=24\right)$, indicating a close coupling between the timing and magnitude of diel periodicities in $\mathrm{P}_{\max }(3.66 \pm 1.13 \mathrm{mg}$ $\left.\mathrm{C} \mathrm{mg} \mathrm{Chl} a^{-1} \mathrm{~m}^{-3} \mathrm{~h}^{-1}\right)$ and $\alpha(0.36 \pm 0.15 \mathrm{mg} \mathrm{C} \mathrm{mg}$ $\left.\mathrm{Chl} a^{-1} \mathrm{~m}^{-3} \mathrm{~h}^{-1} / \mu \mathrm{E} \mathrm{m} \mathrm{m}^{-2} \mathrm{~s}^{-1}\right)$. Such tight coupling has been documented often for diel periodicities in temperate latitude phytoplankton (Harding et al. 1982; Prézelin 1992), several species of which have a biolo-

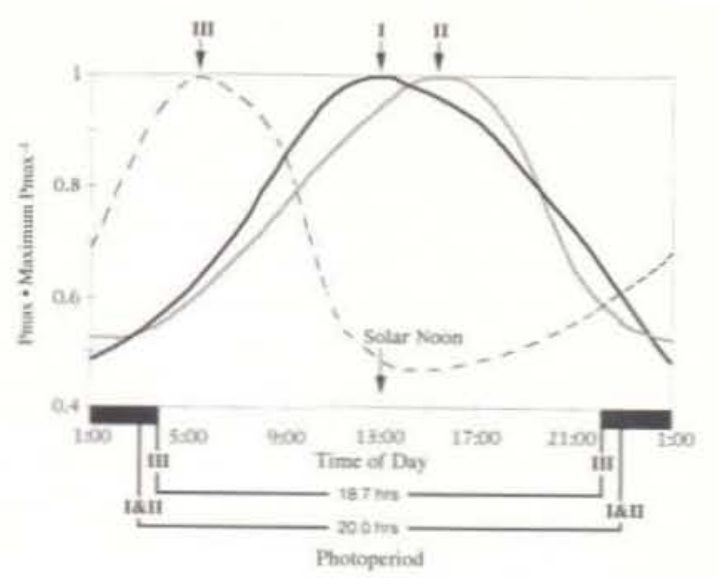

Fig. 8 Diel patterns determined for $P_{\max }: \max P_{\max }$ at LTER Sta. B from 10 December 1991 to 21 January 1992. Pattern $I$ is representative of early spring and diatom bloom samples collected above the FML Pattern II is representative of diatom-dominated samples collected below the FML for the first 2 months of sampling. Pattern III is representative of the cryptophyte bloom that occurred within the FML in the middle of January 1992 (see Fig. 7). The mean daylength for each pattern is presented so that the relationship between the peak $P_{\operatorname{mas}}$ activity and the timing of dawn/dusk and solar noon may be discerned

gical clock regulating the daytime timing of peak photosynthetic capabilities (Prézelin 1992).

The diel periodicities for $\mathrm{Chl} a$ max communities (ca. $15 \mathrm{~m}$ ) during the diatom bloom (Fig. 8, pattern II) were very similar to those resolved for surface samples (Fig. 8, pattern I). $\mathrm{P}_{\max }$ changed two-fold over the day with dawn and dusk values about $55-60 \%$ of $\max P_{\max }$. However, unlike surface communities, $\mathrm{Chl} a$ max communities displayed their maximum photosynthetic potential in the early afternoon, about $1-2 \mathrm{~h}$ after solar noon. Again, $\alpha$ values covaried with $\mathrm{P}_{\max }(3.54 \pm 1.54$ $\mathrm{mg} \mathrm{C} \mathrm{mg} \mathrm{Chl} a^{-1} \mathrm{~m}^{-3} \mathrm{~h}^{-1} ; n=30$ ), but with lower $I_{k}$ values for these deeper diatoms communities $\left(84 \pm 17 \mu \mathrm{E} \mathrm{m}^{-2} \mathrm{~s}^{-1}\right)$.

Diel periodicity in carbon fixation was incorporated into final primary production estimates (see below). The monthly primary production estimate for December, representing the bulk of the diatom bloom, was $79 \mathrm{~g} \mathrm{C} \mathrm{m}^{-2}$. Daily integrated rates were greatest in late December, reaching a value of almost $7 \mathrm{~g} \mathrm{C} \mathrm{m}^{-2} \mathrm{~d}^{-1}$ (Fig. 10B), when estimates of radiation utilization efficiencies (Schofield et al. 1994) indicated that the phytoplankton within the bloom were operating at near maximal photosynthetic quantum efficiencies,

Early summer and the demise of a diatom bloom, followed by a near-surface cryptophyte bloom with an early morning peak in photosynthetic potential

In January 1992, there was a rapid transition from a diatom-dominated bloom to one dominated by 
cryptophytes (alloxanthin) in both the surface and Chl $a$ max (Fig. 6). The depth of the Chl $a$ max, however, had shallowed from a depth of ca. $15 \mathrm{~m}$ within the UML to a depth of ca. $5 \mathrm{~m}$ within the FML (Fig. 7) and it was almost completely dominated by cryptophytes between JD 10 and 20 (Fig. 6C). The cryptophyte bloom was restricted to the near-surface low salinity waters, with the pycnocline between the FML and deeper waters separating it from the remnants of the prior diatom bloom (Moline et al. 1996). The highest Chl $a$ concentration for the entire season $(29.2 \mathrm{mg}$ $\mathrm{Chl} a \mathrm{~m}^{-3}$ ) was recorded in the shallow Chl $a$ max on 11, January 1992 (Fig. 6A). Light attenuation was particularly high within the cryptophyte bloom, perhaps due to global flowing and appeared to have an effect on the photoadaptive state of the phytoplanktons. $I_{k}$ values only at the surface, $68 \pm 26 \mu \mathrm{E} \mathrm{m} \mathrm{m}^{-2} \mathrm{~s}^{-1}$ $(n=8) ; \mathrm{I}_{\mathrm{k}}$ at the $\mathrm{Chl} a$ max was $46 \pm 9 \mu \mathrm{E} \mathrm{m} \mathrm{m}^{-2} \mathrm{~s}^{-1}$ $(n=9)$ for the Chl $a$ max. While surface $\mathrm{Chl} a$ concentrations were high, primary production was less during this period than during the previous diatom bloom (Fig. 10, see below). The intense near-surface cryptophyte bloom persisted for approximately 2 weeks until strong storm-related wind forcing advected the water mass out of the area.

Independent determinations of diel variations in P-I parameters for the surface and $\mathrm{Chl} a$ max samples collected on 14 and 21 January revealed a single pattern (III) for the cryptophyte-dominated community (Fig. 8). Diel pattern III was remarkably different from those observed for diatom communities a few weeks earlier in the season (Fig. 8). Timing of peak $\mathrm{P}_{\max }$ during the cryptophyte bloom occurred near dawn, or $7-8 \mathrm{~h}$ before solar noon. In midafternoon, when $\mathrm{P}_{\max }$ values would have been highest for diatom-dominated communities, $\mathrm{P}_{\max }$ values in the cryptophyte community were at a daily minimum.

A very dilute diatom-dominated community was present below $15 \mathrm{~m}$ and the cryptophyte bloom. This community was low-light adapted, with an average $\mathrm{I}_{\mathrm{k}}$ of $44 \pm 15 \mu \mathrm{E} \mathrm{m}^{-2} \mathrm{~s}^{-1}(n=10)$, or about half that of diatoms in the $\mathrm{Chl} a$ max during the diatom bloom (see above). Direct measurements of diel periodicities of photosynthesis in this deeper remaining diatom community were not made. For subsequent daily integrated production estimates, we applied the pattern of diel periodicity in $\mathrm{P}_{\max }$ and $\alpha$ determined for the Chl $a$ max during the diatom bloom in December, assuming that the two diatom communities had identical diel periodicities. This assumption was based on photophysiological similarities between the deep communities during and just after the diatom bloom (Schofield et al. 1994). If we erred in this assumption, the impact on the primary productivity estimates would be small given the low biomass and low photosynthetic activity at the base of the euphotic zone (Fig. 4).
Mid-summer mixed phytoplankton communities, unstable water columns and shifting diel patterns of photosynthesis

Storm activity from late January through the 1st week of February 1992 generated strong winds and heavy precipitation, resulting in the advection of the cryptophyte bloom water mass from the region (Moline et al. 1996). The advected water mass was replaced by one that was slightly warmer and nutrient replete, and containing dilute $\left(<0.5 \mathrm{mg} \mathrm{Chl} a \mathrm{~m}^{-3}\right)$ mixed communities of diatoms, prymnesiophytes and other flagellated chromophytes ( $\mathrm{Chl} c$-containing phytoplankton). In particular, there was a significant increase in chrysophytes (19'-butanoyloxyfucoxanthin) (Fig. 6). High attenuation of $\mathrm{Q}_{\mathrm{par}}$ continued after the advection of the cryptophyte/diatom bloom from Sta. B (Figs. 4B, 5 ), due largely to the presence of glacial flour in the meltwater of the upper 5-10 m (Smith et al. 1992a; Moline et al. 1996).

Diel pattern IV was resolved for these mixed communities in the 4 th week of January, and was sufficiently distinctive from other patterns to require separate consideration in seasonal productivity estimates (Fig. 9). A single diel pattern of photosynthesis was resolved for the surface and Chl $a$ max during this period of rapid change with a $\max _{\max }$ late in the afternoon. For pattern IV, represented by JD 28, the $\mathrm{I}_{\mathrm{k}}$ values for the surface and $\mathrm{Chl} a$ max were $85 \pm 18 \mu \mathrm{E}$ $\mathrm{m}^{-2} \mathrm{~s}^{-1}(n=6)$ and $52 \pm 2 \mu \mathrm{E} \mathrm{m}^{-2} \mathrm{~s}^{-1}(n=4)$ respectively. Once again, $I_{k}$ values were relatively constant over the day with $\mathrm{P}_{\max }$ of $1.22 \pm 0.8 \mathrm{mg} \mathrm{C} \mathrm{mg} \mathrm{Chl} a^{-1}$ $\mathrm{m}^{-3} \mathrm{~h}^{-1}$ for the surface and $2.46 \pm 1.33 \mathrm{mg} \mathrm{C} \mathrm{mg} \mathrm{Chl}$ $a^{-1} \mathrm{~m}^{-3} \mathrm{~h}^{-1}$ for the Chl $a$ max.

There was a radically different diel $\mathrm{P}_{\max }$ pattern the following week. Comparing pattern IV with pattern $\mathrm{V}$ (Fig. 9), the timing of $\max P_{\max }$ apparently shifted some $12 \mathrm{~h}$ to peak near dawn, much like the earlier cryptophyte bloom. The magnitude of the daytime changes in $\mathrm{P}_{\max }$ remained at about two-fold and $\mathrm{I}_{\mathrm{k}}$ values determined for the surface and $\mathrm{Chl} a$ max were $91 \pm 26 \mu \mathrm{E} \mathrm{m}^{-2} \mathrm{~s}^{-1}(n=9)$ and $76 \pm 18 \mu \mathrm{E} \mathrm{m} \mathrm{m}^{-2} \mathrm{~s}^{-1}$ $(n=6)$ respectively. Although there was a slight increase in the relative abundance of prymnesiophytes (Fig. 6), there is no apparent taxonomic, hydrographic (aside from salinity) or photophysiological explanation for the large and real shift in peak timing of $\max P_{\max }$ between pattern IV and V.

By the 1st week in February, major wind events had subsided and there was a temporary decrease in the UML depth (Fig. 7). The mixed phytoplankton community, comprised of diatoms, prymnesiophytes, chrysophytes and cryptophytes, remained in the water column. However, there was a shift toward increasing dominance by prymnesiophytes at the expense of chrysophytes (Fig. 6). Once again the diel patterns in photosynthesis shifted significantly. Diel pattern VI resolved the daytime variation in $\mathrm{P}_{\max }$ for samples 


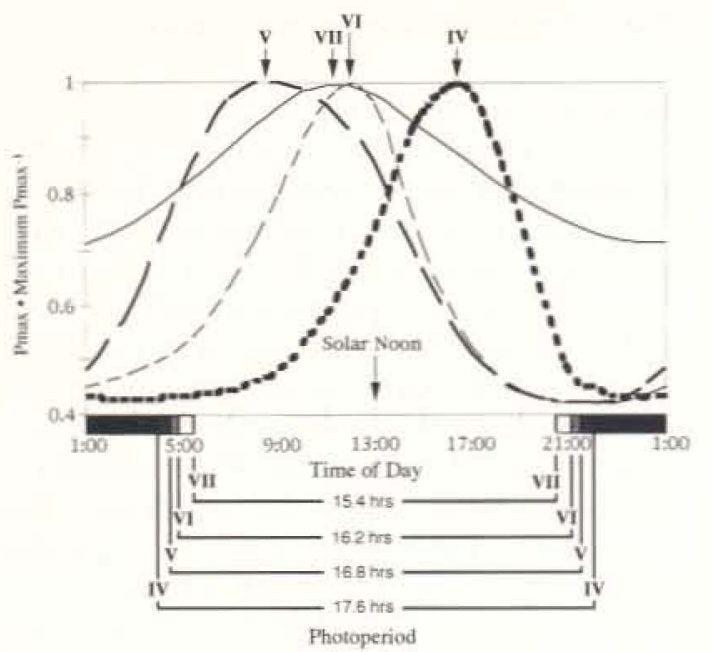

Fig. 9 Diel patterns determined for $\mathrm{P}_{\max }: \max \mathrm{P}_{\max }$ at LTER Sta. B from 21 January 1992 to 25 February 1992 (see Fig. 7). Patterns $I V, V$ and $V I$ are representative of mixed phytoplankton communities advected through the region during a strong wind-mixing event. Pattern VII is representative of the re-emergence of a diatom-dominated phytoplankton community during late summer restratification of the water column. The mean daylength for each pattern is presented so that the relationship between the peak $\mathrm{P}_{\max }$ activity and the timing of dawn/dusk and solar noon may be discerned

collected from the surface and Chl $a$ max on 4 February (JD 35), as well as for the surface sample collected on 10 February (JD 41). Maximum photosynthetic potentials for these communities were at solar noon with a twofold variation over the day (Fig. 9).

The Chl $a$ max sample collected below the FML on 10 February (JD 41), like the surface sample collected the same day, also displayed a midday peak in $\max P_{\max }$ (pattern VII, Fig. 9). The magnitude of the diel periodicity in $\mathrm{P}_{\max }$, however, was dampened compared to all other previous patterns, with $\mathrm{P}_{\max }$ varying $25-30 \%$ over the day. Diel patterns for samples collected from the surface and $\mathrm{Chl} a$ max on 10 February were different despite no significant differences in the community structure between depths (Fig. 5). $\mathrm{I}_{\mathrm{k}}$ values were similar for the surface $\left(63 \pm 6 \mu \mathrm{E} \mathrm{m}{ }^{-2} \mathrm{~s}^{-1}, n=5\right)$ and $\mathrm{Chl}$ $a \max \left(64 \pm 21 \mu \mathrm{E} \mathrm{m}^{-2} \mathrm{~s}^{-1}, n=6\right)$, suggesting photoacclimation to similar light fields during the previous period of high wind mixing.

Late summer, restratification and re-emergence of diatom dominance with a midday peak in photosynthetic potential

Pattern VII was representative not only of the Chl $a$ max community on 10 February, but also of the diatom-dominated communities that re-emerged during the last 10 days of our seasonal monitoring program at LTER station B (Fig. 6). With gradually increasing water-column stability and restratification, integrated $\mathrm{Chl} a$ concentrations increased from 35 to $93 \mathrm{mg} \mathrm{Chl} a \mathrm{~m}^{-2}$. Again, $\mathrm{I}_{\mathrm{k}}$ values for the surface $\left(66 \pm 7 \mu \mathrm{E} \mathrm{m}^{-2} \mathrm{~s}^{-1}, n=8\right)$ and $\mathrm{Chl} a \max (63 \pm 14 \mu \mathrm{E}$ $\mathrm{m}^{-\frac{1}{2}} \mathrm{~s}^{-1}, n=15$ ) were not significantly different.

\section{Simulated in situ primary production estimates}

The seven diel photosynthetic patterns for each P-I parameter were applied to the instantaneous P-I parameters and the in situ $Q_{\text {par }}$ light field measured over the season (Fig. 7). Diel-corrected estimates of simulated in situ daily integrated primary productivity for Sta. $\mathrm{B}$ were derived according to Equation 1 or 2 and are shown in Fig. 10A. A most striking feature was the elevated production during the bloom. The highest daily production $\left(0.75 \mathrm{~g} \mathrm{C} \mathrm{m}^{-3} \mathrm{~d}^{-1}\right)$ occurred at $7.5 \mathrm{~m}$ on 30 December 1991 when $\mathrm{Chl} a$ concentrations were $25.0 \mathrm{mg} \mathrm{m}^{-3}$. As with the phytoplankton biomass (Fig. 4A), productivity decreased at Sta. B in mid-January after the advection of the bloom from the area and increased again at the end of the sampling season with increasing water-column stability (Fig. 7). Depth-integrated productivity estimates for the season were significantly correlated with integrated biomass $(P<0.001)$, showing peak values during the bloom (Fig. 10B). Peak integrated productivity was $6.3 \mathrm{~g} \mathrm{C} \mathrm{m}^{-2} \mathrm{~d}^{-1}$ with a total integrated production for the season of $135 \mathrm{~g}$ $\mathrm{C} \mathrm{m}^{-2}$. December had the highest calculated integrated monthly productivity $\left(79 \mathrm{~g} \mathrm{C} \mathrm{m}^{-2}\right)$ with decreased carbon fixation as the season progressed (January, $36 \mathrm{~g} \mathrm{C} \mathrm{m}^{-2}$; February, $19 \mathrm{~g} \mathrm{C} \mathrm{m}^{-2}$ ). An average of

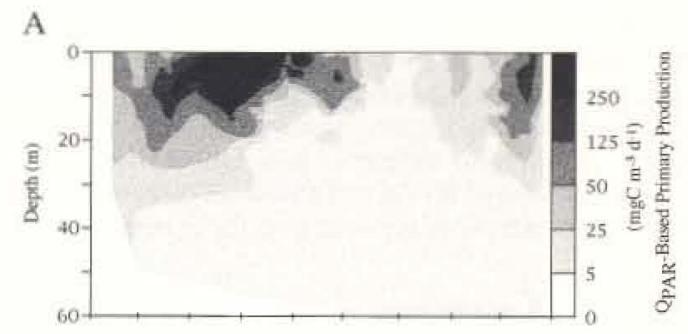

B

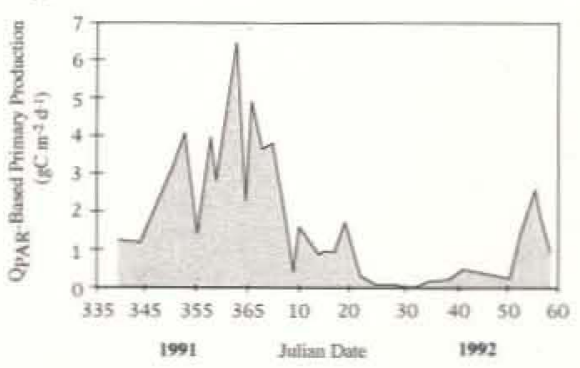

Fig. 10A Depth and time distribution of daily simulated in situ $Q_{\text {par }}$-based productivity over the austral summer of 1991/1992 at LTER Sta. B. B Seasonal changes in daily integrated water column productivity, based on $\mathrm{Q}_{\text {par }}$-dependent measurements of rates of carbon fixation 
$56 \pm 13 \%$ of the water column productivity was lightsaturated over the season, and despite occasionally high in situ irradiances (Fig. 5A), only $3 \%$ of the samples were photoinhibited $\left(\mathrm{Q}_{\text {par }}>\mathrm{I}_{\mathrm{t}}\right)$.
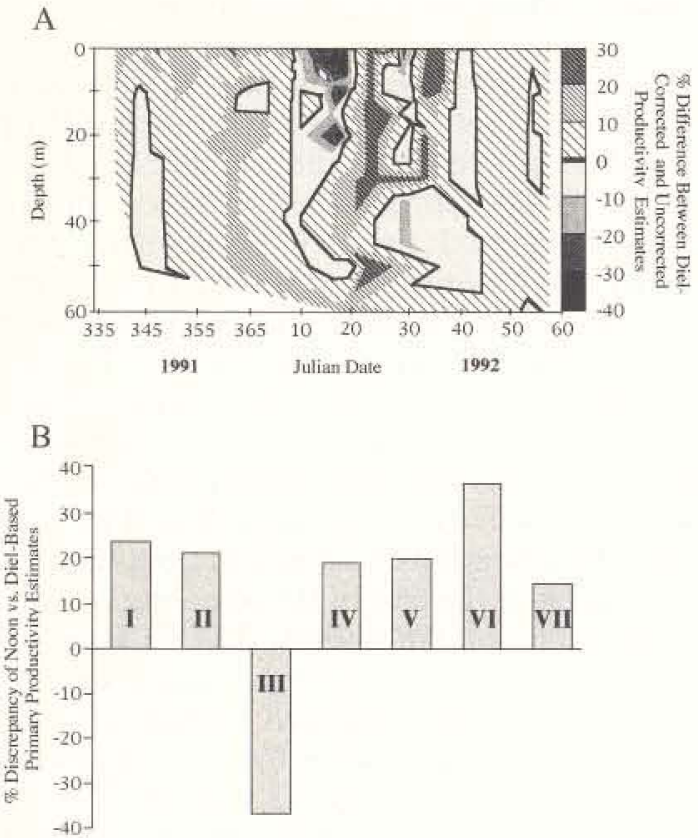

Fig. $11 \mathrm{~A}$ The depth and time distribution at LTER Sta. B of the percent difference between estimates of daily primary productivity based solely on instantaneous measurements versus those that have been time-corrected for diel periodicity in P-I parameters. Positive values represent times and depths where production estimates, based upon a single measurement made sometime between midmorning and late afternoon, overestimate those measurements where diel periodicity in photosynthesis has been considered, and vice versa. B Comparison of percent difference between estimates of daily integrated rates of primary production based solely on derived noon-time estimates of P-I parameters that are held constant over the day and those based upon estimates of diel variations in P-I parameters. The percent difference between the two productivity estimates was calculated for each of the seven different diel pattterns (Figs. 8,9) of photosynthesis resolved over the season at LTER Sta. B
Diel effects on estimates of daily integrated production

When productivity estimates based solely on the instantaneous P-I parameters and the $Q_{\text {par }}$ light field were compared to those considering the seven diel patterns applied at particular depth and time intervals over the season (indicated in Fig. 7), significant differences of $\pm 30 \%$ were apparent throughout the water column (Fig. 11A). This difference was found despite the attempt over the season to center sample collection around solar noon. Water-column productivity was overestimated by instantaneous P-I parameter estimates most of the season, with the significant exception of the period in mid-January when a population of cryptophytes dominated the water column.

Diel-corrected daily productivity estimates for this study were further compared to those based solely on midday P-I parameter values (Fig. 11B). Noon-based estimates simulate synoptic coverage and could be comparable to estimates made from satellite measurements collected on fixed time intervals. Similar to the instantaneous P-I parameter estimates, noon-based productivity overestimated diel-corrected production an average of ca. $20 \%$. As with the instantaneous estimates, the minimum photosynthetic potential for pattern III occurred at solar noon and noon-based productivity showed an underestimation of $37 \%$ for the near-surface cryptophyte population during January.

Table 1 summarizes results of the diel-corrected productivity compared to productivity estimates based on instantaneous P-I parameters and midday values for different time scales over the season at Sta. B. Most notable are the large differences between the diel-corrected and the midday productivity estimates over all time intervals (column E). Differences between the dielcorrected and the instantaneous productivity estimates (column C) were smaller and tended to increase as the time interval was shortened. Interestingly, diel correction of instantaneous productivity data integrated over the season resulted in only a $7 \%$ difference.
Table 1 Integrated production ( $\mathrm{g} \mathrm{C} \mathrm{m}^{-2}$ ) at Station B for various time intervals from December 1991 to February 1992. Column A, P-I parameters vary over the day based on diel measurements; column B, P-I parameters constant over the day at their time of sampling; column $\mathrm{C}$, percent difference bewteen column $\mathrm{A}$ and $\mathrm{B}$; column D, P-I parameters constant over the day at midday values; column $\mathrm{E}$, percent difference between column $\mathrm{A}$ and $\mathrm{D}$

\begin{tabular}{llllll}
\hline $\begin{array}{l}\text { Time } \\
\text { interval }\end{array}$ & $\begin{array}{l}\text { A } \\
\text { diel } \\
\text { Corrected }\end{array}$ & $\begin{array}{l}\text { B } \\
\text { No } \\
\text { correction }\end{array}$ & $\begin{array}{l}\mathrm{C} \\
\% \text { difference } \\
(1-\mathrm{A} / \mathrm{B})\end{array}$ & $\begin{array}{l}\mathrm{D} \\
\text { Midday } \\
\text { corrected }\end{array}$ & $\begin{array}{l}\mathrm{E} \\
\% \text { difference } \\
(1-\mathrm{A} / \mathrm{D})\end{array}$ \\
\hline Season & 134.6 & 144.8 & +7.1 & 220.4 & +38.9 \\
Month & 79.2 & 88.4 & +10.4 & 134.9 & +41.3 \\
Dec 91 & 36.0 & 36.4 & +1.1 & 54.1 & +327 \\
Jan 92 & 19.3 & 20.0 & +3.4 & 31.4 & +36.3 \\
Feb 92 & & & & & \\
Week & 36.0 & 30.3 & +11.4 & 46.5 & +34.8 \\
21-28 Dec 91 & 1.0 & 1.1 & +13.2 & 1.6 & +32.4 \\
21-28 Jan 92 & 12.1 & 12.3 & +2.1 & 17.1 & +27.9 \\
21-28 Feb 92 & & & & & \\
Day & 2.8 & 3.1 & +11.6 & 4.7 & +41.3 \\
24 Dec 92 & 0.1 & 0.1 & +28.2 & 0.2 & +47.7 \\
24 Jan 92 & 2.6 & 2.6 & -1.0 & 3.7 & +29.8 \\
24 Feb 92 & & & & &
\end{tabular}




\section{Discussion}

The high-resolution data derived from our 1991/1992 austral spring/summer monitoring of LTER Station $\mathrm{B}$ document the high variability in primary productivity for this coastal region on time scales ranging from hours to seasons. While previous studies in the Antarctic have reported diel variation in photosynthesis (Rivkin and Putt 1988) and productivity on longer time scales (Horne et al. 1969; Whitaker 1982; Rivkin 1991), this is one of the first studies to integrate results across these time scales. In doing so, we were able to resolve the significance of hourly, daily and weekly variations on subseasonal and seasonal primary productivity estimates. Furthermore, we were able to elucidate some of the underlying phytoplankton group-specific photophysiological characteristics that contributed to the observed temporal variability in primary production and associated effects on chemical and optical properties of the water column. Lastly, on time scales of a few days to seasons, we documented the close biologicalphysical coupling between phytoplankton productivity and water-column stability at this long-term ecosystem monitoring site. The format for data analyses presented here has been repeated for the two subsequent years (1992/93 and 1993/94) in order to test the robustness of our seasonal observations from 1 year to the next.

\section{Diel periodicity of photosynthesis}

Diel periodicity of photosynthesis at LTER Sta. B was observed throughout the sampling period, with significant temporal variability in timing of peak photosynthetic potential $\left(\max P_{\max }\right)$ over the day. Photosynthetic potentials for phytoplankton at Sta. $\mathrm{B}$ varied by up to $55 \%$ of the maximum over the day and the timing of the maximum ranged between 0500 and 1700 hours LT over the season. Similar results for Antarctic diatoms have been found in McMurdo Sound, with the maximum photosynthetic potential varying by up to $80 \%$ of the maximum over the day (Rivkin and Putt 1988). The timing of the maximum for the Mc Murdo diatoms shifted from midday to midnight and was suggested to be dependent on the change in photoperiod during the spring/summer transition. Diel periodicity of photosynthesis at Sta. B, however, did not change with photoperiod, but appeared to be mostly consistent with changes in phytoplankton community composition throughout the season. Previous work has shown a species-specific diel response in diatoms isolated from McMurdo Sound (Rivkin and Putt 1988), further suggesting that diel patterns vary with community composition changes.

Temporal dynamics at Sta. B showed that the community composition changes were dependent on the water-column stability and water-mass type (Moline et al. 1996). Spatial studies in the Southern Ocean have reported similar findings with single species dominance associated with particular regions and water masses (Sommer 1988; Estrada and Delgado 1990; Mura et al. 1995). The majority of primary productivity measurements made in the Antarctic are spatial studies crossing many different water types and phytoplankton communities, with sampling occurring at different times of day and without opportunities to determine diel variations in productivity parameters. If, as this study suggests, diel periodicity is shown to be largely dependent on community composition, the absence of these diel measurements in diverse waters may have a very significant impact upon the calculated production estimates and interpretation of the data. The greatest effects would be seen in communities that show a large variation in daily potential photosynthetic response and have a diel maximum that is offset from time of sampling.

Although diel periodicities of photosynthesis in this study were closely coupled to the community composition, there was evidence to indicate that periodicity was also related to the mixing regimes. Diel patterns within a fixed phytoplankton community were subtly different if surface and Chl $a$ max communities were separated by a pycnocline. During the bloom, surface and Chl $a$ max samples were collected from the FML and the UML, respectively, and different diel patterns were found at the two depths (Fig. 7). This was also the case on 10 February (JD 41) when the depth of the UML shallowed to ca. $35 \mathrm{~m}$. These differences in periodicity were found with no apparent difference in the community composition (Fig. 6) and may have been a result of unique physical conditions (i. e. salinity, temperature) existing within the two layers. Over the course of this study, when both the surface and Chl $a$ max samples were taken from the same mixed layer (i. e. FML), the diel periodicities displayed the same patterns.

\section{Knowledge of diel periodicity in carbon fixation} significantly increased the accuracy of productivity estimates over time scales ranging from a day to several weeks

Knowledge of specific timing and diel variation in photosynthetic potential over the season at Sta. B were shown to alter production estimates by $\pm 30 \%$ or greater on any given day during the season (Fig. 11, Table 1). The largest effect was seen for cryptophyte populations when the magnitude of photosynthetic potential was high $(55 \%)$ and the timing of the maximum was furthest from local solar noon. With the effect of diel periodicity on daily estimates as high as $\pm 30 \%$, there was a potential for a large effect on the timeintegrated estimates. For the present study, however, the effect of diel periodicity on weekly, monthly and seasonally integrated productivity was less (ca. 10\%) 
resulting from the combination of over- and underestimates (Table 1). Previously reported potential effects of diel periodicity on productivity measurements for temperate oceans (Harding et al. 1982; Prézelin et al. 1987; Smith et al. 1987; Prézelin and Glover 1991) and the Southern Ocean (Rivkin 1987) agree well with the range reported here, further emphasizing the importance for diel correction of instantaneous measurements, especially during periods of high productivity.

\section{High sampling frequency provided robust determinations of time-integrated primary productivity}

Recently, Taylor and Howes (1994) documented the effect of sampling frequency on seasonal primary productivity estimates for a temperate coastal embayment. They showed that by sampling at intervals of 5 days or less (as in the present study), the sampling-frequencyinduced (SFI) error was equivalent to the error limit of the analytical method. However, sampling intervals to the order of 14-30 days, as in many Antaretic studies, produced an SFI error of $\pm 35 \%$. According to Taylor and Howes (1994), studies such as that of Whitaker (1982) with five samples taken over a 100-day period, would have estimated SFI errors of ca. $\pm 30 \%$. The study by Horne et al. (1969) at the same location. sampling every 5.2 days, would have an estimated SFI error of ca. $\pm 5 \%$. Similarly, error estimates for our study due to sampling frequency would be below $5 \%$. SFI errors, however, are dependent on the variability in the system measured. The above estimates are based on the variability in the system measured by Taylor and Howes (1994), and therefore, they do not necessarily reflect the effect of sampling frequency in Antarctic coastal waters.

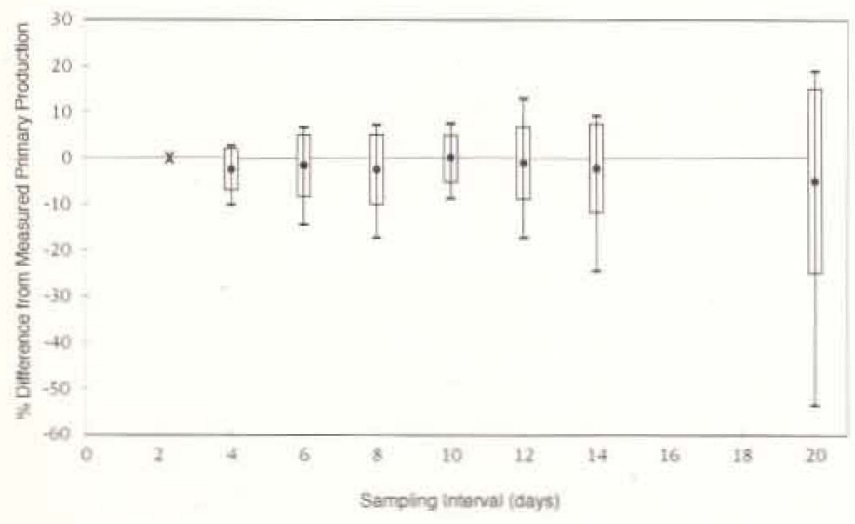

Fig. 12 Examination of the effect of sampling frequency on the accuracy of estimates of primary productivity at LTER Sta. B during the austral summer of 1991/1992. The mean (filled circles), standard deviation (unfilled box) and range (certical lines) of the percent difference from the measured seasonal productivity $\left(135 \mathrm{~g} \mathrm{C} \mathrm{m}^{-2}\right)$ are shown for sampling intervals ranging from every 2.3 days to every 20 days
We determined simulated in situ productivity for Sta. $\mathrm{B}$ on time scales not previously measured in the Antarctic (2- to 3-day intervals) and was adequately resolved to examine the SFI error. In order to estimate the SFI error at Sta. B, the measured depth-integrated daily productivity was subsampled at different intervals over the season. The primary productivity measured for this study ( $135 \mathrm{~g} \mathrm{C} \mathrm{m}^{-2}$ ) on 2- to 3-day intervals was considered to be the "true" productivity and was used as the reference for estimates made for the different sampling frequencies. Sampling intervals, ranging from 4 to 20 days, were applied to the measured data, starting from the 1st day of sampling in December 1991. The starting time for each subsampling interval was then sequentially moved 1 day later over a range of 15 days, resulting in 15 data subsets. These 15 data subsets revealed the range of variability in the SFI errors for each sampling interval and accounted for the particular seasonal dynamics at Sta. B. Productivity estimates were found to vary significantly based on sampling interval and the time at which the seasonal integration begins (Fig. 12). The percent difference from the measured productivity increased with the sampling interval, ranging from ca. $\pm 5 \%$ for the 4 -day sampling interval to $\pm 50 \%$ for the 20 -day sampling interval. The major bloom event in late December 1991, responsible for ca. $65 \%$ of the seasonal production at Sta. B, occurred on a time scale less than 3 weeks. By sampling at identical intervals (i. e. 20 days), the productivity associated with these events can be entirely missed. At Sta. B, had we implemented a sampling interval of 20 days, we could have underestimated seasonal productivity by as much as $50 \%$ (Fig. 12). These SFI errors are generally higher than those reported by Taylor and Howes (1994), suggesting that the temporal variability in integrated primary productivity for Antarctic coastal regions may be higher than that for temperate coastal regions.

Incorporation of diel measurements in daily integrated rates of primary productivity, combined with high sampling frequency, provided accurate and reliable seasonal production estimates for coastal waters of the Southern Ocean

Given the effort and evaluations documented herein, we believe our estimates of primary production to be accurate and reliable for long-term monitoring. Daily rates of primary productivity at LTER Sta. B varied consistently with biomass at discrete depths throughout the water column $(P<0.001)$, for integrated biomass $(P<0.001)$ and incident $\mathrm{Q}_{\mathrm{par}}(P=0.05)$, with peak production occurring during the massive coastal bloom. $\mathrm{Q}_{\text {par }}$-dependent production rates during the bloom $\left(0.75 \mathrm{~g} \mathrm{C} \mathrm{m}^{3} \mathrm{~d}^{-1}\right.$ and $\left.6.3 \mathrm{~g} \mathrm{C} \mathrm{m}^{-2} \mathrm{~d}^{-1}\right)$ are some of the highest recorded for the Antarctic. Blooms 


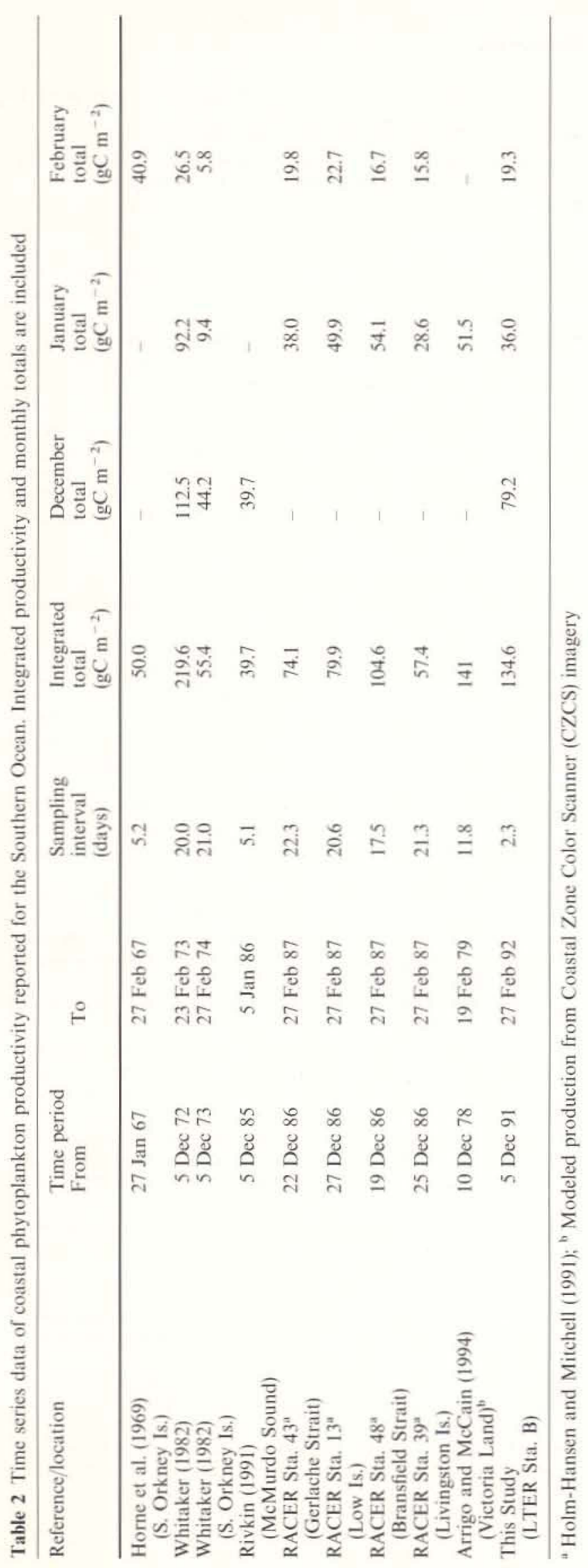

such as this one are not uncommon near Anvers Island (Shabica et al. 1977; Krebs 1983; Holm-Hansen et al. 1989) and in other near-shore environments (Horne et al. 1969; Whitaker 1982). Previous studies have attributed elevated levels of biomass to enhanced watercolumn stability, low grazing pressure, and micro-element enrichment from land runoff (Holm-Hansen et al. 1989; Mitchell and Holm-Hansen 1991). Although there are no data in the present study to provide comment on possible micro-element enrichment, watercolumn stability was found to be a major factor responsible for high biomass and productivity at Sta. B (Moline et al. 1996).

The pattern of seasonal change (spring bloom, midsummer low productivity, fall increase) looks remarkably like generalized changes occurring at temperate latitudes. Here, however, the observed changes over the 1991/1992 season were driven by very different patterns of physical/chemical/optical forcing than those described for temperate latitude seasonal succession of phytoplankton (Harris and Piccinin 1980; Harris 1986). As detailed in Moline et al. (1996), the mechanisms for enhanced water-column stability initiating the bloom formation were a combination of ice/snow meltwater lens and decreased wind speeds. Light and nutrient limitation set the upper limit of biomass accumulation and productivity during the bloom. After the bloom was advected from the region, a period of strong winds and intense mixing kept biomass and production low from mid-January until the end of February. Unlike temperate latitudes, grazing and nutrient limitation during this time were found not to influence the phytoplankton dynamics (Moline et al. 1996). The UML shallowed with decreasing winds at the end of February and resulted in increased productivity and another significant, but less intense, bloom in March 1992 (K. Habermann, personal communication). This pattern for productivity in the Antarctic has been found previously (Krebs 1983), suggesting not only similar driving forces but also a consistency in the timing of the various driving forces influencing the annual patterns. Interestingly, the seasonal productivity pattern observed in 1991/1992, and reported here, was not seen in preliminary findings from the $1992 / 1993$ and $1993 / 1994$ spring/summer seasons at LTER Sta. B (data not shown), indicating the need for further analyses before generalizations can be made about seasonal and interannual patterns of productivity for coastal Antarctica.

Monthly and seasonal productivity estimates from Sta. B were generally higher compared to other productivity time series data for Antarctic coastal regions (Table 2). Total integrated productivity for the season was generally higher, but in the range reported by other studies for the same time interval. The trend of decreasing productivity from December to February held for all studies, but was highly variable. Comparing results of these different time-series studies is difficult and depends on methods, location of sampling, frequency of 
sampling and the materials used. With the exception of this study and that of Arrigo and McCain (1994), samples for the time-series studies listed in Table 2 were incubated in situ using borosilicate glass bottles. This material does not transmit light below ca. $324 \mathrm{~nm}$, thus decreasing exposure to ultraviolet radiation (UVR). Recent studies have quantified the effects of UVR on natural Antarctic phytoplankton populations, with emphasis on biologically damaging UVB radiation due to the decrease in stratospheric ozone $\left(\mathrm{O}_{3}\right)$ concentrations (Smith et al. 1992b; Prézelin et al. 1993a; Prézelin et al. 1994). Although the effects of decreasing $\mathrm{O}_{3}$, and associated increases in UVB radiation, on integrated phytoplankton production have been estimated at between 6 and 12\% (Smith et al. 1992b), the effects of natural background UVR have been estimated to decrease daily surface production by $60-70 \%$ (El-Sayed et al. 1987; Prézelin et al. 1994) and integrated production by ca. $23 \%$ (Boucher 1994). Inhibition of primary production by UVR is not included for any of the estimates listed in Table 2, and is beyond the scope of this study. It is, however, potentially important when deriving and comparing seasonal productivity estimates (Boucher and Prézelin 1996).

In conclusion, we have quantified the seasonal carbon fixation for an Antarctic coastal site and have documented the large temporal variability associated with these highly productive environments. We have also shown that high-frequency sampling strategies, which include some accommodation for diel photosynthetic periodicity, are prerequisites for accurate determinations of seasonal primary production in the Southern Ocean. It is clear that before long-term (i. e. years to several decades) "signals", which indicate trended changes in primary production, in any region of the ocean brought on by climate change, can be irrefutably determined, some knowledge of the "noise" reflecting significant variations on shorter time scales (days, months, seasons) is required. Addressing sources of potentially large errors, such as diel photosynthetic periodicity and sampling frequency, in productivity estimates, helps to better define the natural variability in the ecosystem, and provides a baseline for future interpretation of long-term trends in phytoplankton dynamics in the Southern Ocean.

Acknowledgements N. Boucher, P. Handley, T. Newberger, K. Seydel, K. Scheppe and the ASA personnel at Palmer Station are acknowledged for their assistance in data collection during the field season. We thank R. Bidigare and M. Ondrusek for generously providing HPLC training and pigment standards. N. Boucher and H.A. Matlick provided valuable technical assistance during the analyses of data. They, together with $\mathrm{H}$. Claustre and O. Schofield, participated in valuable discussions and provided editorial comments that significantly improved the manuscript. We would also like to thank O. Holm-Hansen and two anonymous reviewers for their constructive and helpful comments. Research was supported by National Science Foundation grant DPP $90-901127$ to B.B. Prézelin. This is Palmer LTER publication number 48.

\section{References}

Arrigo KR, McCain CR (1994) Spring phytoplankton production in the Western Ross Sea. Science 266:261-263

Bidigare RR, Schofield O, Prézelin BB (1989) Influence of zeaxanthin on quantum yield of photosynthesis of Synechococcus clone WH7803 (DC2). Mar Ecol Prog Ser 56:177-188

Bidigare RR, Iriarte JL, Kang S-H, Ondrusek ME, Karentz D, Fryxell GA (1995) Phytoplankton: quantitative and qualitative assessments. In: Ross R, Hofmann E, Quetin L (eds) Foundations for ecosystem research in the Western Antarctic Peninsula Region. Antarctic Research Series, American Geophysical Union, Washington, DC

Bodungen B von, Smetachek V, Tilzer MM, Zeitzschell B (1986) Primary production and sedimentation during spring in the Antarctic Peninsula region. Deep Sea Res 33:177-194

Boucher NP (1994) Antarctic phytoplankton primary production under enhanced flux of ultraviolet radiation: a bio-optical approach. PhD Thesis, University of California, Santa Barbara

Boucher NP, Prézelin BB (1996) Spectral modeling of UV inhibition of in situ Antaretic primary productivity using a newly derived biological weighting function. Photochem Photobio (in press)

Caceci MS, Cacheris WP (1984) Fitting curves to data. Byte $9: 340-362$

Claustre H, Moline MA, Prézelin BB (1996) Sources of variability in the column photosynthetic cross section for Antarctic coastal waters. J Geophys Res (in press)

El-Sayed SZ, Weber LH (1982) Spatial and temporal variations in phytoplankton biomass and primary production in the Southwest Atlantic and the Scotia Sea. Polar Biol 1:83-90

El-Sayed SZ, Biggs DC, Holm-Hansen O (1983) Phytoplankton standing crop, primary productivity, and near-surface nitrogenous nutrient fields in the Ross Sea, Antarctica. Deep Sea Res 30:871-886

El-Sayed SZ, Stephens FC, Bidigare RR, Ondrusek ME (1987) Effects of ultraviolet radiation on Antarctic marine phytoplankton. In: Kerry KR, Hempel G (eds) Antarctic ecosystems. Springer, Berlin Heidelberg New York, pp 379-385

Estrada M, Delgado M (1990) Summer phytoplankton distributions in the Weddell Sea. Polar Biol 10:441-449

Harding LW, Prézelin BB, Sweeney BM, Cox JL (1982) Primary productivity as influenced by diel periodicity of phytoplankton photosynthesis. Mar Biol 61:95-105

Harris GP (1986) Phytoplankton ecology: structure, function and fluctuation. Chapman \& Hall, London

Harris GP, Piccinin BB (1980) Physical variability and phytoplankton communities. IV. Temporal changes in the phytoplankton community of a physically variable lake. Arch Hydrobiol $89: 447-473$

Helbling WE, Villafañe VE, Holm-Hansen O (1995) Variability of phytoplankton distribution and primary production around Elephant Island, Antarctica, during 1990-1993. Polar Biol $15: 233-246$

Holm-Hansen O, Mitchell BG (1991) Spatial and temporal distribution of phytoplankton and primary production in the western Bransfield Strait region. Deep Sea Res 38:961-980

Holm-Hansen O, El-Sayed SZ, Franceschini GA, Cuhel RL (1977) Primary productivity and the factors controlling phytoplankton growth in the Southern Ocean. In: Llano GA (ed) Adaptations within Antarctic ecosystems. Gulf, Houston, pp 11-50

Holm-Hansen O, Mitchell BG, Hewes CD, Karl DM (1989) Phytoplankton blooms in the vicinity of Palmer Station, Antarctica, Polar Biol 10:49-57

Horne AJ, Fogg GE, Eagle DJ (1969) Studies in situ of the primary production of an area of inshore Antarctic Sea. J Mar Biol Assoc UK 49:393-405

Kamykowski D, Zentara S-J (1989) Circumpolar plant nutrient covariation in the Southern Ocean: patterns and processes. Mar Ecol Prog Ser 58:101-111 
Krebs WN (1983) Ecology of neritic marine diatoms, Arthur Harbor, Antarctica. Micropaleontology 29:267-297

Mitchell BG, Holm-Hansen O (1991) Observations and modeling of the Antarctic phytoplankton crop in relation to mixing depth. Deep Sea Res 38:981-1007

Moline MA, Prézelin BB (1994) Palmer LTER: impact of a large diatom bloom on macronutrient distribution in Arthur Harbor during austral summer 1991-1992. Antarct J U S 29:217-219

Moline MA, Prézelin BB, Schofield O, Smith RC (1996) Temporal dynamics of coastal Antarctic phytoplankton: environmental driving forces and impact of a 1991-1992 summer diatom bloom on the nutrient regimes. In: Battaglia B, Valencia J, Walton DWH (eds) Antarctic communities. Cambridge University Press, Cambridge

Morel A (1991) Light and marine photosynthesis: a spectral model with geochemical and climatological implications. Prog Oceanogr 26:263-306

Mura MP, Satta MP, Agusti S (1995) Water-mass influences on summer Antarctic phytoplankton biomass and community structure. Polar Biol 15:15-20

Neale PJ, Richerson PJ (1987) Photoinhibition and the diurnal variation of phytoplankton photosynthesis. I. Development of a photosynthesis-irradiance model from studies of in situ responses. J Plankton Res 9:167-193

Prezelin BB (1992) Diel periodicity in phytoplankton productivity. In: Berman T, Gons HJ, Mur LR (eds) The daily growth cycle of phytoplankton. Kluwer, Dordrecht Boston London, pp 1-35

Prézelin BB, Glover HE (1991) Variability in time/space estimates of phytoplankton biomass and productivity in the Sargasso Sea. J Plankton Res 13S:45-67

Prézelin BB, Bidigare RR, Matlick HA, Putt M, VerHoven B (1987) Diurnal patterns of size-fractioned primary productivity across a coastal front. Mar Biol 96:563-574

Prézelin BB, Glover HE, VerHoven B, Steinberg DK, Matlick HA. Schofield O, Nelson NB, Wyman M. Campbell L (1989) Bluegreen light effects on light-limited rates of photosynthesis: relationship to pigmentation and productivity estimates from the Sargasso Sea. Mar Ecol Prog Ser 54:121-136

Prézelin BB, Boucher NP, Moline MA. Stephens E, Seydel K. Scheppe K (1992a) Palmer LTER program: spatial variability in phytoplankton distribution and surface photosynthetic potential within the peninsula grid, November 1991. Antarct J U S 27:242-245

Prézelin BB, Moline MA, Seydel K, Scheppe K (1992b) Temporal variability in HPLC pigmentation and inorganic nutrient distribution in surface waters adjacent to Palmer Station, December 1991-February 1992. Antarct J U S 27:242-245

Prézelin BB, Boucher NP, Smith RC (1993a) Daytime of UV-A and UV-B inhibition of photosynthetic activity in Antarctic surface waters. In: Yamamoto HY, Smith CM (eds) Photosynthetic responses to the environment, current topics in plant physiology. Am Soc Plant Physiol 2:150-155

Prézelin BB. Nelson NB. Schofield O, Boucher NP, Smith RC, Waters K, Bidigare RR, Lewis MR, Baker KS, Stegmann P (1993b) Bio-optics in U.S. JGOFS: handbook of bio-optical nomenclature. U.S. JGOFS Planning Report \#18, U.S. JGOFS Planning Office, Woods Hole, pp 159-165

Prézelin BB, Boucher NP, Smith RC (1994) Marine primary production under the influence of the Antarctic ozone hole: Icecolors '90. In: Weiler S, Penhale P (eds) Ultraviolet radiation and biological research in Antarctica. American Geophysical Union, Washington DC, pp 159-186
Rivkin RB (1987) Diel periodicity of photosynthesis in polar phytoplankton: potential influence on primary production. Science 238: $1285-1288$

Rivkin RB (1991) Seasonal patterns of planktonic production in McMurdo Sound, Antarctica. Am Zool 31:5-16

Rivkin RB, Putt M (1988) Seasonal pattern of diel periodicity in photosynthesis by polar phytoplankton: species-specific responses. J Phycol 24:369-376

Ross RM, Quentin LB (1992) Palmer long-term ecological research (LTER): an overview of the 1991-1992 season. Antarct J U S 27:235-236

Sakshaug E, Slagstad D, Holm-Hansen O (1991) Factors controlling the development of phytoplankton blooms in the Antarctic Ocean-a mathematical model. Mar Chem 35:259-271

Schofield O, Prézelin BB, Smith RC, Stegmann PM, Nelson NB, Lewis MR, Baker KS (1991) Variability in spectral and nonspectral measurements of photosynthetic light utilization efficiencies. Mar Ecol Prog Ser 78:253-271

Schofield O, Moline MA. Prézelin BB (1994) Photoadaptation in a coastal phytoplankton bloom and impact on the radiation utilization efficiency for carbon fixation. Antarct J U S 29;214-216

Shabica SV, Hedgpeth JW, Park PK (1977) Dissolved oxygen and $\mathrm{pH}$ increases by primary production in the surface water of Arthur Harbor, Antarctica, 1970-1971. In: Llano GA (ed) Adaptations within Antarctic ecosystems. Gulf, Houston, pp 83-97

Smith RC, Bidigare RR, Prézelin BB, Baker KS, Brooks JM (1987) Optical characterization of primary productivity across a coastal front. Mar Biol 96:574-591

Smith RC, Prézelin BB, Bidigare RR, Baker KS (1989) Bio-optical modeling of photosynthetic production. Limnol Oceanogr 34:1526-1546

Smith RC, Baker KS, Handley P, Newberger T (1992a) Palmer LTER program: hydrography and optics within the peninsula grid, zodiac sampling grid during the 1991-1992 field season. Antarct J U S 27:253-255

Smith RC, Prézelin BB, Baker KS, Bidigare RR, Boucher NP, Coley T, Karentz D, Maclntyre S, Matlick HA, Menzies D, Ondrusek M, Wan Z, Waters KJ (1992b) Ozone depletion: ultraviolet radiation and phytoplankton biology in Antarctic water. Science 255:952-959

Smith WOJ, Nelson DM (1985) Phytoplankton bloom produced by a receding ice edge in the Ross Sea: spatial coherence with the density field. Science 277:163-166

Smith WOJ, Sakshaug E (1990) Polar phytoplankton. In: Smith WOJ (ed) Polar oceanography; part A: physical science, part B: chemistry, biology, geology. Academic Press, San Diego, pp 477-526

Sommer U (1988) The species composition of Antarctic phytoplankton interpreted in terms of Tilman's competition theory. Oecologia 77:464-467

Taylor CD, Howes BJ (1994) Effect of sampling frequency on measurements of seasonal primary productivity and oxygen status in near-shore coastal ecosystems. Mar Ecol Prog Ser 108:193-203

Whitaker TM (1982) Primary production of phytoplankton off Signy Island, South Orkneys, the Antarctic. Proc R Soc London 214:169-189

Wilson DL, Smith WO, Nelson DM (1986) Phytoplankton bloom dynamics of the western Ross Sea ice edge. I. Primary productivity and species specific production. Deep Sea Res 33:1375-1387

Zimmerman RC, SooHoo JB, Kremer JN, D'Argenio DZ (1987) Evaluation of variance approximation techniques of non-linear photosynthesis-irradiance models. Mar Biol 95:209-215 